\title{
THE KINETICS OF SILVER BROMIDE FILM FORMATION ON THE SILVER ANODE
}

\author{
VIOLA I. BIRSS \\ Chemistry Department, University of Ottawa, Ottawa, Ontario, Canada \\ and \\ GRAHAM A. WRIGHT \\ Chemistry Department, University of Auckland, Auckland, New Zealand
}

(Received 22 December 1981)

\begin{abstract}
The anodic potentiodynamic formation of an $\mathrm{AgBr}$ film on an $\mathrm{Ag}$ rotating disc electrode was studied in aqueous bromide solutions. As the electron transfer step (1) is intrinsically fast,

$$
\mathrm{Ag}+\mathrm{Br}^{-} \rightleftharpoons \mathrm{AgBr}+e^{-},
$$

and as the film remains porous throughout its growth, the rate of film growth is limited by physical parameters such as ionic diffusion and migration in the solution.

The anodic $E$ / I curves for $\mathrm{AgBr}$ film formation were calculated quantitatively by computer on the basis of the following model of film growth. Film formation occurs initially by the nucleation of islands of film to a critical thickness, and then these islands spread laterally until only small pores remain between them. As these pores become small, the resistance of the solution within them becomes rate limiting (at the anodic current peak). After the peak, the concentration of bromide ions at the pore base falls to zero and current is then controlled by the diffusion of bromide ions into the lengthening pores of the film.

This lateral spreading mechanism and the subsequent retention of the porous film morphology has been substantiated by comprehensive Scanning Electron Microscope investigations.
\end{abstract}

\section{INTRODUCTION}

There has been a considerable amount of interest in the past in the anodic formation of silver halide films on silver electrdes.

$$
\mathrm{Ag}+X_{(\mathrm{aq})}^{-} \rightleftharpoons \mathrm{Ag} X_{\text {(film) }}+e^{-} ; X=\mathrm{Cl}, \mathrm{Br}, \mathrm{I} .
$$

This is due, in particular, to the use of $\mathrm{Ag} / \mathrm{AgCl}$ electrodes in sea water batteries and dry cells[1], to the wide usage of the silver halide reference electrodes[2] and to the general application of silver halides in photography[3]. Therefore, an understanding of the mechanism and kinetics of $\operatorname{Ag} X$ film growth and information regarding the morphology of these films has been sought.

In the past, anodically formed silver halide films were formed only under galvanostatic conditions, with the main conclusion being that the $\operatorname{Ag} X$ films are highly porous in nature, especially when they are thin and when they are formed at high current densities $(c d)$.

The galvanostatic formation of $\operatorname{Ag} X$ films was initially studied by $\mathrm{Kurtz}[4]$, who found $\mathrm{AgCl}$ and $\mathrm{AgBr}$ films to be highly porous when formed at $c d$ 's less than about $2.5 \mathrm{~mA} \mathrm{~cm}^{-2}$ and up to a limiting film thickness. On the basis of microscopic examinations and differences in the volumes of $\mathrm{Ag}$ and $\mathrm{AgCl}$, Briggs et al.[5] concluded that all $\mathrm{AgCl}$ films, as well as the reduced $\mathrm{Ag}$, must be porous in nature. It was concluded in[5] that when about $0.1 \%$ of the total electrode surface is covered by $\mathrm{AgCl}, 99^{\circ}$ of the current will still pass through the pores of the film. Jaenicke et al. $[6,7]$ and Awad[8] carried out galvanostatic and microscope studies of the growth and the reduction of silver halide and silver sulfide films. Porosity was observed in films thinner than a few microns, and again, when the films were formed at high rates.

Fleischmann and Thirsk[9] also found that $\mathrm{AgCl}$ deposits which were formed galvanostatically on $\mathrm{Ag}$ were generally non-passivating, with scanning electron micrographs (SEM) of the $\mathrm{AgCl}$ deposits appearing very similar to those given for $\mathrm{AgBr}$ films in the present research. A 2-dimensional growth scheme was proposed for $\mathrm{AgCl}$ film formation, with the reaction rate being controlled by the rate of $\mathrm{AgCl}$ deposition on the $\mathrm{Ag}$ surface. Giles[10] concluded also that $\mathrm{AgCl}$ films were porous but that the growth of $\mathrm{AgCl}$ deposits was a 3-dimensional process.

Bro and Marincic[11] studied $\mathrm{AgCl}$ films formed at very high $c d$, and interpreted the observed boiling of the electrolyte as being due to transport limitations in the pores of the films. Bishop and Riley[12] also found that the growth of thick $\mathrm{AgBr}$ films occurs by ion transport in the pores of the film, with a subsequent depletion of bromide ions in the pores.

In contrast to the above observations, Lal et al.[13] found no evidence for film porosity in silver halide films and instead measured an increasing film resistance with increasing film thickness over a wide range of applied $c d$. Also contrary to most of the work discussed above, Indira and Doss[14] observed an $\mathrm{AgCl}$ film porosity at low $c d$ of film formation and non-porosity at high applied $c d$ 's.

The galvanostatic deposition of $\mathrm{AgCl}$ on a porous Ag electrode was also studied by comprehensive 
modelling of the $\mathrm{Ag} / \mathrm{AgCl}$ electrode by Katan. Szpak, Dunning et al.[15-20]. It was found that the coverage of $\mathrm{Ag}$ by $\mathrm{AgCl}$ occurred to a greater extent near the electrode/electrolyte interface rather than in the electrode interior[16]. Also, the appearance of the deposit changed at a critical depth into the electrode[18], consistent with a change in the rate determining step with increased film growth.

In this work, the anodic formation of $\mathrm{AgBr}$ films by the potentiodynamic method has been investigated in aqueous bromide solutions. A similar study of anodically formed $\mathrm{Ag}_{2} \mathrm{~S}$ films on an $\mathrm{Ag}$ electrode under potentiodynamic conditions has recently been published $[21,22]$. It is the purpose of this paper to describe and elucidate the mechanism and the kinetics of the growth of these $\mathrm{AgBr}$ films under these conditions and to correlate this with the observed film morphology as seen by SEM. Also, it will be shown that the potentiodynamically obtained $E / I$ curves can be very closely simulated on the basis of the appropriate model of anodic film growth.

\section{EXPERIMENTAL}

The potentiodynamic experiments were carried out with a conventional 3-electrode potentiostatic circuit (Chemical Electronics TR 70/2A). Potential sweep rates, $s$, were varied between 5 and $300 \mathrm{mVs}^{-1}$, and potential/current $(E / I)$ curves were then plotted on an $X / Y$ recorder or on an oscilloscope.

The working electrode was an Ag (Engelhardt, $5 \mathrm{~N}$ purity) rotating disc electrode $(r d e)$ with an apparent surface area of $0.0234 \mathrm{~cm}^{2}$, embedded in a PVC holder. The auxiliary electrode was a $\mathrm{Pt}$ loop and the reference electrode was a saturated calomel electrode in a Luggin capilary. All potentials are given with respect to the normal hydrogen electrode scale (nhe).

Before each experiment, the electrode surface was treated in a reproducible manner by turning it flat on a lathe, polishing with emery paper (up to 1200 grade) and then rinsing with water, acetone, ethanol and then water again. The roughness factor, $\gamma$, was obtained by double layer capacitance measurements[23] before and after each set of experiments. It was found that $\gamma$ was typically between 2 and 4 for the fresh surface but increased to a value of 100 or more with repeated cycles of film formation and reduction.

Solutions were flushed with nitrogen before and during each experiment. Chemicals used were of AnalaR quality and all water was doubly distilled. All experiments were conducted at temperatures with the range of $18-22^{\circ} \mathrm{C}$.

The electrode surfaces which were examined by SEM were first rinsed with water, dried and then inspected with a JEOL JSM-U3 SEM at $25 \mathrm{kV}$. X-ray fluorescence analysis of the surfaces yielded only silver and bromide peaks in all cases.

\section{RESULTS}

(i) $\mathrm{AgBr}$ film growth at low bromide concentrations

A typical $E / I$ curve for an $\mathrm{Ag}$ rde in a dilute bromide solution can be seen Fig. $1\left(9 \mathrm{mmoll}^{-1} \mathrm{HBr}\right.$ $+0.1 \mathrm{M} \mathrm{NaClO}_{4}$ solution). In the anodic sweep, a

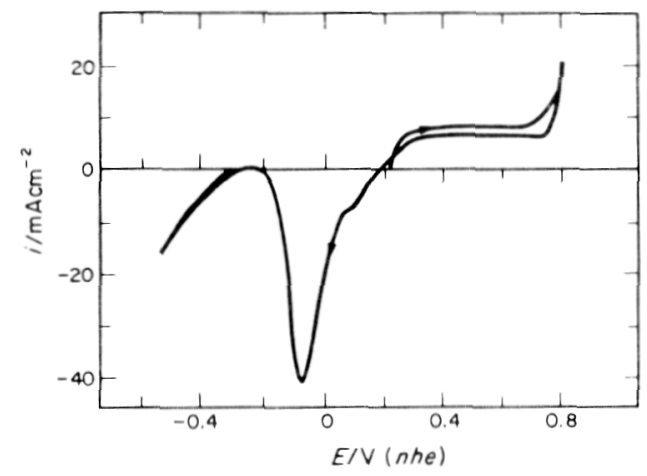

Fig. 1. $E / I$ curve of $\mathrm{Ag}$ rde in $9 \times 10^{-3} \mathrm{moll}^{-1} \mathrm{HBr}$ $+0.1 \mathrm{moll}^{-1} \mathrm{NaClO}_{4}$ at $s=30 \mathrm{mVs}^{-1}$ and $\omega=8 \mathrm{~Hz}$ Anodic plateau $c d$ depends on (o), but not on $s$.

current plateau is obtained for $\mathrm{AgBr}$ formation (1) while the reduction of $\mathrm{AgBr}$ occurs in a fairly sharp current peak. The formation potential, $E_{\mathrm{f}}$ $(=0.22 \mathrm{~V} / n h e)$, the potential midway between the onset of the anodic and the cathodic currents, is very close to the reversible potential for $\mathrm{AgBr}$ formation, $E_{\mathrm{r}}$, which can be calculated by (2)

$$
E_{\mathrm{r}}=0.07-0.059 \log \left(\mathrm{Br}^{-}\right) \mathrm{V} / \text { nhe. }
$$

The current in the anodic current plateau region of Fig. 1 is independent of $s$ but varies linearly with $\omega^{1 / 2}$ as is typical for a diffusion limited reaction. The relationship between the diffusion limited current and $\omega^{1 / 2}$ for a rotating disc electrode can be expressed by the Levich equation (3)[24].

$$
i=0.62 z F D^{2 / 3} v^{-1 / 6} C \omega^{1 / 2},
$$

where $z$ is the number of electrons involved in the reaction $(=1), F$ is the Faraday constant, $D$ is the diffusion coefficient for $\mathrm{Br}^{-}\left(2.1 \times 10^{-5} \mathrm{~cm}^{2} \mathrm{~s}^{-1}[25]\right)$, $v$ is the kinematic viscosity of the solution $(8.9$ $\left.\times 10^{-3} \mathrm{~cm}^{2} \mathrm{~s}^{-1}[26]\right), C$ is the bulk concentration of $\mathrm{Br}^{-}$in the solution and $\omega$ is the rotation speed of the electrode.

A plot of the observed and the calculated (3) relationship between $i$ and $\omega^{1 / 2}$ is shown in Fig. 2, and the close match between them indicates that the rate of the reaction between $\mathrm{Ag}$ and $\mathrm{Br}^{-}$to form $\mathrm{AgBr}$ in dilute bromide solutions is limited by the diffusion of bromide ions to the electrode surface. This is a direct indication that current transport through the growing $\mathrm{AgBr}$ film itself is a relatively fast process, even for films containing up to about 1 Coulomb per apparent $\mathrm{cm}^{2}$.

Figure 1 also shows that at a potential of about $0.75 \mathrm{~V}$, a sharp increase in anodic current is observed. On the basis of the potential at which this occurs and the absence of a cathodic counterpart to this anodic current, this has been determined to be due to the dissolution of $\mathrm{Ag}$ as $\mathrm{Ag}^{+}$according to (4)

$$
\mathrm{Ag} \rightleftharpoons \mathrm{Ag}_{(\mathrm{aq})}^{+}+e^{-} \text {. }
$$

This may indicate that the $\mathrm{Ag}$ surface is not completely covered by the $\mathrm{AgBr}$ film and that the film must therefore be porous in nature. This has been substantiated by an SEM examination of the electrode surface at various stages of $\mathrm{AgBr}$ film growth. Figure 3 


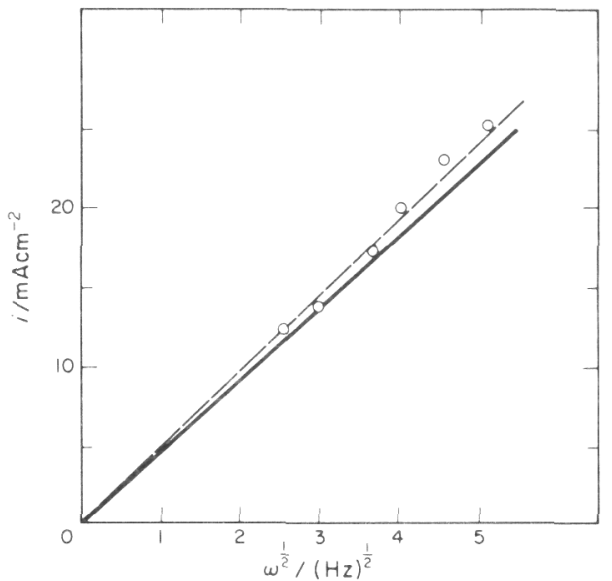

Fig. 2. Experimental (--) and calculated (relationship (3) between plateau $c d$ (Fig. 1) and $\left(01^{1 / 2}\right.$. in $9 \times 10^{-3} \mathrm{moll}^{-1} \mathrm{HBr}+0.1 \mathrm{moll}^{-1} \mathrm{NaCiO}_{4}$ at $s=50 \mathrm{mVs}^{-1}$.

shows the film surface at a potential of $0.55 \mathrm{~V}$, where it can be seen that a very porous and patchy type of film is forming.

At somewhat higher bromide concentrations, such as $0.1 \mathrm{M} \mathrm{HBr}+0.1 \mathrm{M} \mathrm{NaClO}_{4}$, the $E / I$ curves are now different from the curves of Fig. 1(Fig. 4) in that a small anodic peak has now developed with a peak $c d$ dependent to some extent on both $s$ and $\omega$. At a potential of about $0.75 \mathrm{~V}$, evidence for the occurrence of (4) can still be seen even with these thicker films (up to $5 \mathrm{C} \mathrm{cm}^{-2}$ ). As in the more dilute bromide solutions, SEM examinations of the electrode surface in 0.1 and $0.2 \mathrm{M} \mathrm{NaBr}$ solutions (Fig. 5) still show a porous island-like $\mathrm{AgBr}$ deposit.

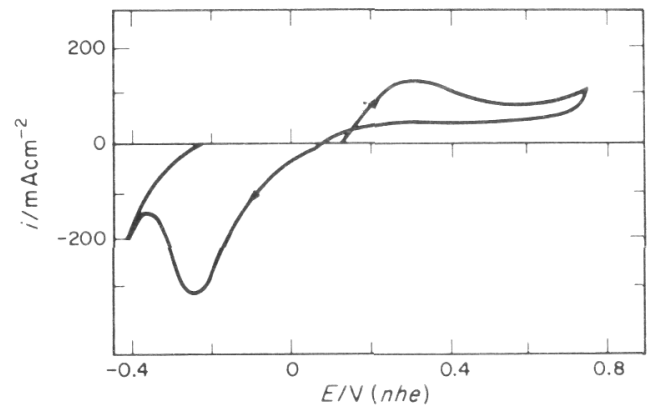

Fig. 4. $E / l$ curve of $\mathrm{Ag} r$ de in $0.11 \mathrm{moll}^{-1} \mathrm{HBr}+0.1 \mathrm{~mol}^{-1}$ $\mathrm{NaClO}_{4}$ at $s=50 \mathrm{mV} \mathrm{s}^{-1}$ and $\omega=10 \mathrm{~Hz}$. Current densities depend to some extent on both $s$ and $\omega$.

In both 0.1 and $0.2 \mathrm{M}$ bromide solutions, the leading edge of the anodic peaks have linear and equal slopes at all $s$ and $\omega$. The reciprocal of this slope has a value which is very close to the calculated ohmic resistance of the solution between the working electrode and the tip of the Luggin capillary, $R_{\mathrm{s}}$, as determined from the Newman equation (5)[27]

$$
R_{\mathrm{s}}=\frac{1}{2 \pi \kappa a} \tan ^{-1}(z / a)
$$

where $z$ is the perpendicular distance between the Luggin capillary and the Ag surface, $a$ is the electrode radius, and $\kappa$ is the conductivity of the solution. That only physical processes such as migration of ions in solution and the diffusion of $\mathrm{Br}^{-}$ions to the electrode surface are rate limiting in these comparitively dilute bromide solutions is an' indication of both the speed of the electron transfer reaction (1) and the lack of resistance offered by these thick $\mathrm{AgBr}$ films. In order to



Fig. 3. SEM view of porous $\mathrm{AgBr}$ film formed on $\mathrm{Ag}$ rde from $9 \times 10^{-3} \mathrm{moll}^{-1} \mathrm{HBr}+0.1 \mathrm{moll}^{-1} \mathrm{NaClO}_{4}$ at $s=100 \mathrm{mV} \mathrm{s}^{-1}$ and $\omega=12 \mathrm{~Hz}$. 


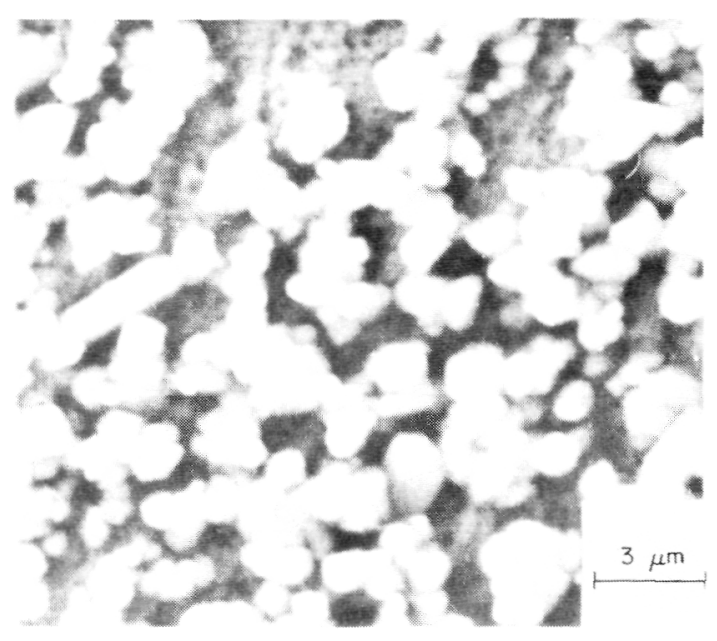

Fig. 5. SEM view of island-like growth of $\mathrm{AgBr}$ film on an $\mathrm{Ag}$ rde from $0.1 \mathrm{moll}^{-1} \mathrm{NaBr}+0.1 \mathrm{moll}^{-1} \mathrm{NaClO}_{4}$ at $s$ $=50 \mathrm{mV} \mathrm{s}^{-1}$ and $\omega=12 \mathrm{~Hz}$.

overcome these physical limitations to the rate of $\mathrm{AgBr}$ film growth, further experiments were carried out in highly conductive solutions of high bromide concentration.

\section{(ii) $\mathrm{AgBr}$ film growth at high bromide concentrations}

Some typical $E / I$ curves for $\mathrm{Ag}$ in more conductive solutions of high bromide concentration such as $1 \mathrm{M} \mathrm{NaBr}+5 \mathrm{M} \mathrm{NaClO}_{4}$ are shown in Fig. 6 at various $s$. Under these conditions, a much more distinct anodic peak is observed, followed by a gradual decline of current despite an increasing potential. At this bromide concentration, large quantities of $\mathrm{AgBr}$ film are being formed and reduced in each complete cycle and the $\mathrm{Ag}$ substrate begins to roughen so that about 5-10 cycles of potential must be completed before a reproducible $E / I$ trace is obtained.

As in more dilute bromide solutions, the observed formation potential is very close in value to the calculated $E_{\mathrm{r}}(2)$ and also, the charges consumed in the

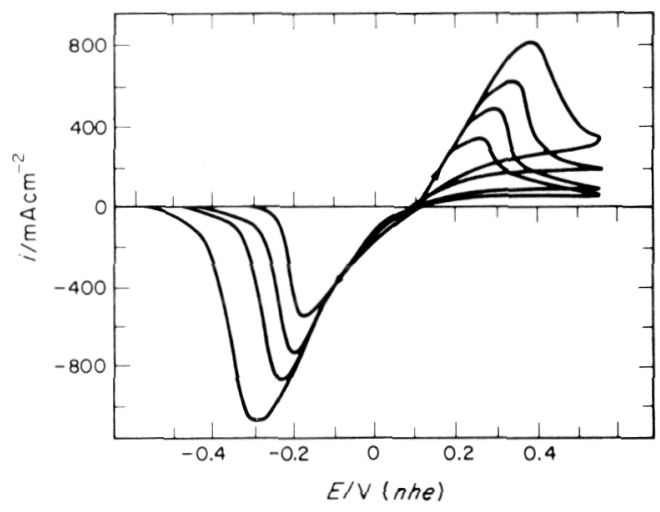

Fig. 6. $E / I$ curves of $\mathrm{Ag} r$ de in $1 \mathrm{moll}^{-1} \mathrm{NaBr}+5 \mathrm{moll}^{-1}$ $\mathrm{NaClO}_{4}$ at $s=50,100,150,300 \mathrm{mV} \mathrm{s}^{-1}$ and $\omega=7 \mathrm{~Hz}$. anodic and cathodic cycles match closely, indicative of the low solubility of $\mathrm{AgBr}$.

It can also be seen from Fig. 6 that, as in the solutions of 0.1 and $0.2 \mathrm{M} \mathrm{Br}^{-}$, the slopes of the leading edge of the anodic peak are all linear and constant under all conditions of $s$ and $\omega$ studied. The value of the reciprocal of the slopes in Fig. 6 is about $12.5 \Omega$, while the calculated value of the solution resistance is about $13 \Omega(5)$. This indicates that even in this more conductive solution, and with these much thicker films, the rate of $\mathrm{AgBr}$ film formation is initially still limited by ion migration in solution rather than by a process within the $\mathrm{AgBr}$ film itself. In an effort to further increase the conductivity of the solution to overcome these migration limitations, experiments were carried out in $1 \mathrm{M} \mathrm{NaBr}+3 \mathrm{M} \mathrm{HClO}_{4}$ solutions, but the observed and calculated resistances were then still approximately the same, ie about $4 \Omega$.

At the anodic peak in Fig. 6, the peak $c d$ is now independent of $\omega$ but depends linearly on $s^{1 / 2}$ (Fig. 7). After the anodic peak, the current then drops gradually, independently of the magnitude of the potential or the direction of the potential sweep. It will be shown below that this behavior is consistent with the potential-independent rate limiting process of ionic diffusion within the pores of the $\mathrm{AgBr}$ film.

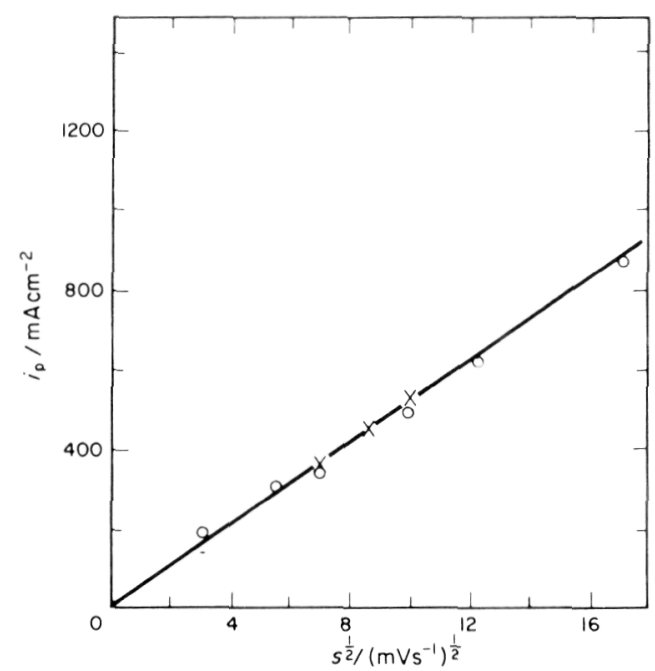

Fig. 7. Experimentally obtained $i_{\mathrm{p}} / s^{1 / 2}$ relationship $\left(\begin{array}{lll}\theta & \ddots & \ddots\end{array}\right)$ for $\mathrm{AgBr}$ film formation in $1 \mathrm{moll}^{-1} \mathrm{NaBr}$ +5 moll $^{-1} \mathrm{NaClO}_{4}$ at $\omega=7 \mathrm{~Hz}$. Calculated relationship $(X)$ is from the Modified Pore Resistance Model (17)

An SEM examination of the $\mathrm{AgBr}$ film formed under conditions such as in Fig. 6 was also carried out. Figures 8 and 9 , respectively, show the surface of the electrode at the anodic peak potential and at a potential of about $0.6 \mathrm{~V}$ in the post-peak region. In both cases, the $\mathrm{AgBr}$ film is clearly very porous rather than compact in nature. It is the purpose of the following treatment to demonstrate how the porous morphology of the $\mathrm{AgBr}$ films and the observed electrochemical behavior are related to the mechanism of $\mathrm{AgBr}$ film growth. 


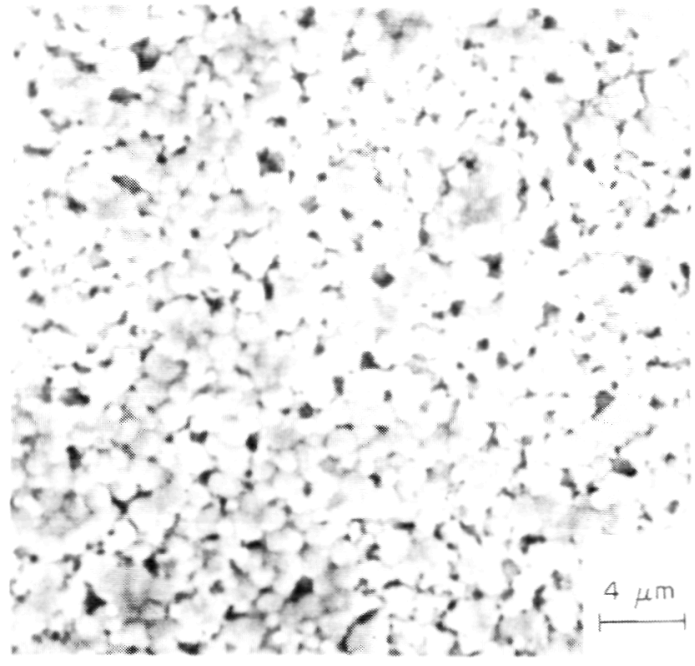

Fig. 8. SEM view of porous $\mathrm{AgBr}$ film formed in $1 \mathrm{moll}^{-1}$ $\mathrm{NaBr}+5 \mathrm{moll}^{-1} \mathrm{NaClO}_{4}$ at $s=100 \mathrm{mV} \mathrm{s}^{-1}, \omega=10 \mathrm{~Hz}$ sweep terminated at the anodic peak (see Fig. 6).

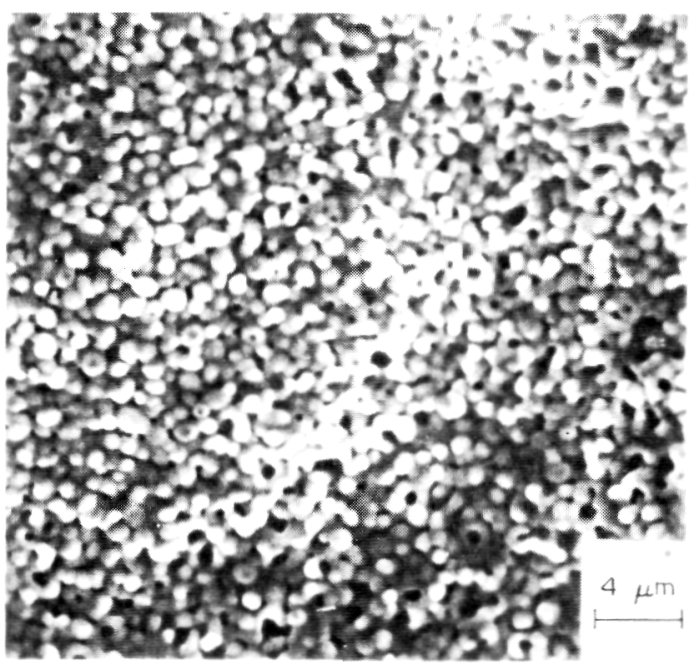

Fig. 9. SEM view showing retention of film porosity for $\mathrm{AgBr}$ film formed as in Fig. 8, but sweep terminated at about $0.6 \mathrm{~V} /$ nhe (see Fig. 6).

\section{MODEL OF AgBr FILM FORMATION UNDER POTENTIODYNAMIC CONDITIONS}

The results of the experiments concerning the growth of $\mathrm{AgBr}$ films under potentiodynamic conditions have shown that even rather thick $\mathrm{AgBr}$ films grow at very high rates while retaining a very porous morphology. These high reaction rates indicate that the electron transfer step (1) must be fast.

As a consequence, in solutions of low bromide concentration, the rate of $\mathrm{AgBr}$ film growth is controlled simply by the diffusion of bromide ions to the Ag electrode surface. At higher bromide concentrations, both ionic migration and diffusion are involved in reaction rate limitations, even in very con- ductive solutions. The following model of $\mathrm{AgBr}$ film growth will show how these physical rate limitations determine the characteristics of the experimentally observed $E / I$ curves and how they are related to the $\mathrm{AgBr}$ film morphology.

(i) Simple model of $\mathrm{AgBr}$ film growth dependent on pore resistance

It was shown above that in solutions of high bromide concentration, the initial rate controlling process in $\mathrm{AgBr}$ film growth is ionic migration in the bulk of the electrolyte, rather than the electron transfer step or a film transport step. Because the films are clearly very porous in nature, Mueller's[28] model of the formation of a porous film has been selected, and a resistance function, originally developed by Arvia et al.[29] for this type of film growth, has been utilized to simulate the observed $E / I$ behavior in the anodic peak region of the $E / I$ curves.

Mueller's model[28] of film growth consists of the initial nucleation of the insoluble species at various random points on the electrode surface, probably at dislocations and defect sites, and the growth of these nuclei to a critical thickness, $l$, and then their lateral spreading until most of the electrode surface is covered. At this point, the resistance of the pores between the spreading islands of film has become rather large and therefore, the current density is expected to drop at this stage of film growth. Katan[16] has observed by SEM that $\mathrm{AgCl}$ deposits initially form as crystallites all having about the same height, thus supporting this lateral spreading mechanism.

The resistance of the pore network during its development, $R_{\mathrm{p}}$, has been given by Arvia[29]

$$
R_{\mathrm{p}}=\frac{1}{\kappa A(1-\theta)},
$$

where $k$ is the solution conductivity, $l$ is the height of the islands of film, $\theta$ is the fraction of the surface covered by the film and $A(1-\theta)$ represents the total pore area. In addition, the resistance of the electrolyte, $R_{\mathrm{s}}$, should be considered while it is assumed that the Faradaic resistance of the reaction is comparatively small.

When an overpotential, $\eta\left(=E-E_{\mathrm{r}}\right)$ is applied to the electrode, and current $I$ flows, Ohm's law can then be applied

$$
I=i A=\frac{\eta}{\left(R_{\mathrm{s}}+R_{\mathrm{p}}\right)}
$$

As the film spreads at a constant thickness, Faraday's law can be expressed as in (8)

$$
I=\frac{z F \rho l A}{M} \frac{\mathrm{d} \theta}{\mathrm{d} t}=k \frac{\mathrm{d} \theta}{\mathrm{d} t},
$$

where $z$ is the number of electrons transferred per molecule of film material $(=1), \rho$ is the film density $\left(6.5 \mathrm{gcm}^{-3}\right)$ and $M$ is the film molecular weight $\left(188 \mathrm{~g} \mathrm{~mole}^{-1}\right)$. Under potentiodynamic conditions, $\eta$ increases linearly with time

$$
\eta=s t \text {. }
$$


By combining (7-9), (10) is obtained

$$
\frac{\mathrm{d} \theta}{\mathrm{d} t}=\frac{s t}{k\left[R_{s}+\frac{l}{\kappa A(1-\theta)}\right]}
$$

By solving (10) numerically, $\theta$ can be obtained as a function of time, and then $I$ can be calculated as a function of time from (6 and 7).

The $I / \eta$ relationship resulting from this calculation can be seen in Fig. 10 along with the experimentally obtained $I / E$ curves. Initially, the current increases linearly, with a reciprocal slope equal to $R_{\mathrm{s}}$. As the pore area decreases with increasing film spreading, the pore resistance, $R_{\mathrm{p}}$, increases, as is evident by the development of the current peak.

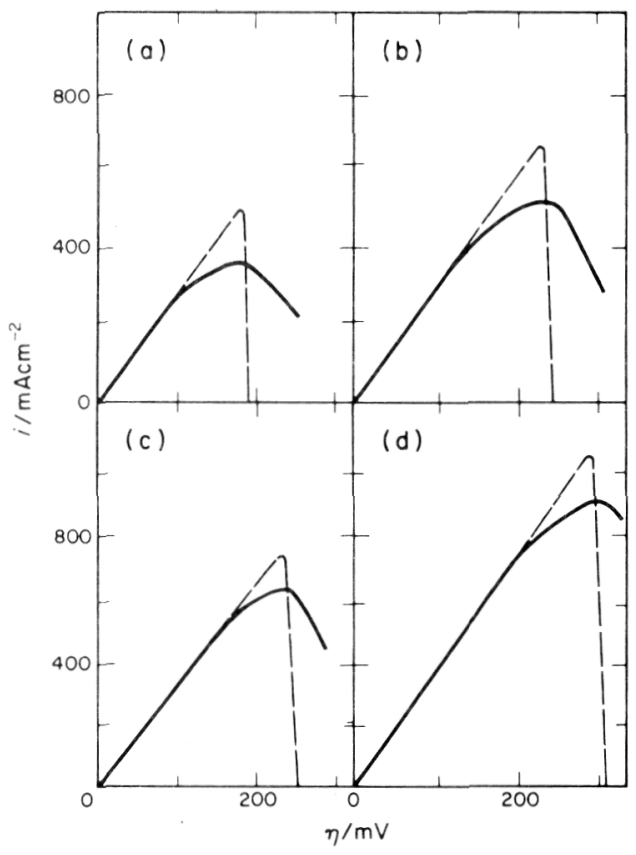

Fig. 10. Comparison of experimental $(-)$ and calculated (--) anodic peaks for the Simple Pore Resistance Model (7) of $\mathrm{AgBr}$ film growth. $s=$ (a) $50, \quad$ (b) $100, \quad$ (c) 150 , (d) $300 \mathrm{mV} \mathrm{s}^{-1}, \quad \omega=7 \mathrm{~Hz}, \quad 1 \mathrm{moll}^{-1} \mathrm{NaBr}+5 \mathrm{moll}^{-1.1}$ $\mathrm{NaClO}_{4}$.

The current at the peak, $I_{\mathrm{p}}$, at a potential $E_{\mathrm{p}}$, occurs when $\mathrm{d}^{2} \theta / \mathrm{d} t^{2}=0$. Therefore, by differentiation of (10), (11) can be obtained, which shows that the peak current should be proportional to $s^{1 / 2}$ for this pore resistance model

$$
I_{\mathrm{p}}=\left(\frac{z F \rho \kappa}{M}\right)^{1 / 2} A\left(1-\theta_{\mathrm{p}}\right) s^{1 / 2} .
$$

This relationship has been confirmed experimentally (Fig. 7) and from the slopes of the plots in Fig. 7, $\theta_{\mathrm{p}}$, the fraction of the surface covered at $E_{\mathrm{p}}$, has been found to be equal to 0.96 . The film thickness or the height of the islands of film at the current peak can be found from the charge density, $q_{\mathrm{p}}$, consumed up to $E_{\mathrm{p}}$ from (12)

$$
l=\frac{q_{\mathrm{p}} M}{z F \rho \theta_{\mathrm{p}}} .
$$

From this, $l$ has an average value of $1.6 \times 10^{-4} \mathrm{~cm}$.

After the anodic peak, the calculated pore resistance (6) increases very rapidly, causing a sudden drop of current almost to zero (Fig. 10). In comparison, the experimental curves show a broader peak than the calculated curves, with the current decreasing much more slowly after the peak. Thus, the agreement between the experimental and the calculated current/potential curves is not very satisfactory in this regard. Therefore, the following modification has been made to the simple film spreading model. Now the film is considered to both thicken and spread simultaneously in a more natural way in the region of the $E / I$ curves leading to the anodic peak.

\section{(ii) Modified pore resistance model}

The modification that has been made to the simple film spreading model and its associated pore resistance is that allowance has now been made for both pore narrowing and pore lengthening up to the anodic current peak. That is, (8) has been modified as (13)

$$
I=k^{\prime} l \frac{\mathrm{d} \theta}{\mathrm{d} t}+k^{\prime} \theta \frac{\mathrm{d} l}{\mathrm{~d} t},
$$

where $k^{\prime}$ is equal to $z F A \rho / M$. Equation (13) contains two time-dependent functions, $\mathrm{d} l / \mathrm{d} t$ and $\mathrm{d} \theta / \mathrm{d} t$. Equation (13) cannot be rearranged to express $\mathrm{d} \theta / \mathrm{d} t$ as a simple function of time as was done in (10) because $\mathrm{d} l / \mathrm{d} t$ is not known. Hence, a somewhat arbitrary but reasonable dependence of $l$ on time has been selected

$$
\frac{\mathrm{d} l}{\mathrm{~d} t}=j^{\prime} \eta
$$

where $j^{\prime}$ is a film thickening rate constant obtained by a computer curve-fitting technique. It is considered to be sensible that the rate of film thickening is proportional to $\eta$, the driving force of the reaction. When (14) is integrated, $(15)$ is obtained

$$
l=\frac{j^{\prime}}{2} s t^{2}+l_{0}=j s t^{2}+l_{0} .
$$

Equation (15) has two arbitrary constants, but both $l_{0}$ and $j$ can be obtained by a best-fit calculation. Equation (13) can now be expressed in terms of (14) and (15)

$$
I=k^{\prime}\left(l_{0}+j s t^{2}\right) \frac{\mathrm{d} \theta}{\mathrm{d} t}+2 k^{\prime} \theta j s t .
$$

As before, the current is considered to be limited by the electrolyte resistance in both the bulk of the solution and in the pores of the film and therefore, (7) can now be expressed as in (17)

$$
I=\frac{s t}{R_{\mathrm{s}}+\frac{l_{0}+j s t^{2}}{\kappa A(1-\theta)}} .
$$

By combining (16) and (17), analagous to the combination of (7) and (8), (18) now expresses $\mathrm{d} \theta / \mathrm{d} t$ as a function of time

$$
\frac{\mathrm{d} \theta}{\mathrm{d} t}=\frac{s t}{\left[R_{\mathrm{s}}+\frac{l_{0}+j s t^{2}}{\kappa A(1-\theta)}\right]\left[k^{\prime} l\right]}-\frac{2 j \theta s t}{l} .
$$


This differential equation was solved numerically by computer for $\theta$ as a function of time by using the parameters $l_{0}=50 \times 10^{-6} \mathrm{~cm}$ and $j=35$ $\times 10^{-8} \mathrm{mV}^{-1} \mathrm{~s}^{-1}$ obtained by a best-fit method. Then, the current was calculated as a function of $\eta$ by (17).

Figure 11 shows the $I / \eta$ curves which were calculated from (17) and the experimentally obtained $I / \eta$ curves. It can be seen that the modification of the pore resistance model to allow for film thickening as well as film spreading has produced a current peak which is more rounded and is a closer approximation to the experimentally obtained curve than for the simple film spreading model. The theoretically obtained $I_{\mathrm{p}} / \mathrm{s}^{1 / 2}$ data points are included in Fig. 5 and can be seen to be very close to the experimentally obtained ones.

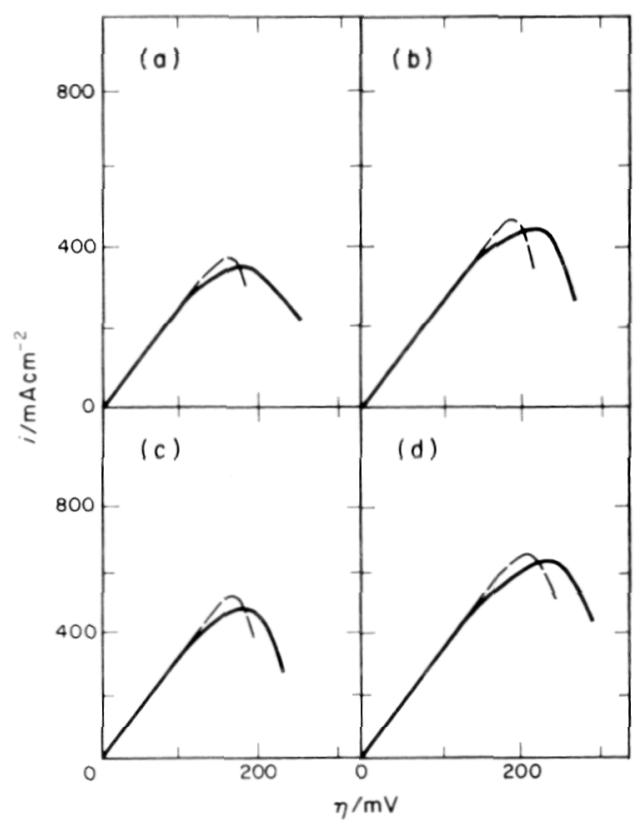

Fig. 11. Comparison of experimental $(-)$ and calculated -) anodic peaks for the Modified Pore Resistance Model (17) of $\mathrm{AgBr}$ film growth; $s=$ (a) 50, (b) 75 , (c) 100 , (d) $150 \mathrm{mV} \mathrm{s}^{-1}$

Overall, the modification to the simple pore resistance model produces a better fit between the calculated and the experimental current/potential curves than did the simple film spreading model. It also represents a more natural progression from a nucleated surface to a surface covered by a thick, porous anodic film.

\section{FILM THICKENING-DIFFUSION IN THE PORES OF THE AgBr FILM}

The potentiodynamic $E / I$ curves (Fig. 6) show that after the anodic peak, $\mathrm{AgBr}$ growth undergoes a change of mechanism from ohmic resistance control to another process which limits film growth. It can readily be seen from Fig. 6 that the post-peak anodic currents decrease gradually in magnitude, even with increasing positive potentials. Also, it can be seen that sweep reversal to the cathodic direction does not significantly alter the current and that it continues to decrease very gradually with time in the same manner as it did in the anodic-going sweep. If the rate of $\mathrm{AgBr}$ film growth were controlled by a field-dependent step in this potential range, then a reversal in the direction of the potential sweep would have resulted in a significant drop in the current, but this is not observed. Therefore, together with the retention of film porosity as seen by SEM (Figs 8 and 9), it is postulated that the diffusion of bromide ions along the pores of the film to the underlying $\mathrm{Ag}$ surface is rate limiting this post-anodic peak region of the $E / I$ curves. Szpak and Katan[19] found that the formation of $\mathrm{AgCl}$ on $\mathrm{Ag}$ spheres underwent a similar change in the rate determining step and this was also confirmed by microscopic evidence of a clear transition in type and quantity of deposit with time and depth into the electrode.

A model of the thickening of the $\mathrm{AgBr}$ films at a rate limited by the diffusion of the halide ions through the long, narrow pores of the silver bromide film to the silver surface is now proposed for the post-peak region of the $E / I$ curves. The transition from the pore resistance control of the current to diffusion controlled current would occur when the concentration of bromide ions at the pore base, $C_{5}$, becomes equal to zero. Therefore, the diffusion current can now be expressed as in (19), which can then be rearranged to give an expression for $C_{\mathrm{s}}(20)$, where $I$ is obtained from (17).

$$
\begin{aligned}
& I=\frac{z F A(1-\theta) D\left(C-C_{\mathrm{s}}\right)}{l}, \\
& C_{\mathrm{s}}=C-\frac{\|}{z F A D(1-\theta)},
\end{aligned}
$$

where $D$ is the diffusion coefficient for the bromide ion, $C$ is the bulk bromide concentration and $l$ is the diffusion length or the pore length.

When this calculation of $C_{\mathrm{s}}$ was carried out, $C_{\mathrm{s}}$ was found to be equal to zero at a potential about $10 \mathrm{mV}$ positive of the anodic peak. But, when $C_{s}$ was equal to zero, $\mathrm{d} \theta / \mathrm{d} t$ (18) was not yet equal to zero. This indicates that further film spreading must still occur but under the control of bromide diffusion within the pores until $\mathrm{d} \theta / \mathrm{d} t$ is equal to zero. Therefore, by rearranging (13-15) and (20), an expression for $\mathrm{d} \theta / \mathrm{d} t$ under diffusion control is obtained

$$
\frac{\mathrm{d} \theta}{\mathrm{d} t}=\frac{D M C(1-\theta)}{l^{2} \rho}-\frac{2 \theta j s t}{l} .
$$

Once $\mathrm{d} \theta / \mathrm{d} t$ is equal to zero (21), only film thickening can then occur and $\theta$ in (19) would then remain constant at $\theta_{\mathrm{f}}$ (the value of $\theta$ when $\mathrm{d} \theta / \mathrm{d} t$ is equal to zero). A typical value of $\theta_{\mathrm{f}}$, obtained at $s=50 \mathrm{mVs}^{-1}$, is 0.978 . The rate of film thickening will then be controlled by the diffusion of bromide ions to the base of the pores of the $\mathrm{AgBr}$ film, as $C_{\mathrm{s}}$ and $\mathrm{d} \theta / \mathrm{d} t$ are both equal to zero. Equation (13) is now replaced by (22) and together with (23), the rate of film thickening 
under diffusion control is expressed as in (24).

$$
\begin{gathered}
I=\frac{\mathrm{d} Q}{\mathrm{~d} t}=k^{\prime} \theta_{\mathrm{f}} \frac{\mathrm{d} l}{\mathrm{~d} t}, \\
I=\frac{z F A D C\left(1-\theta_{\mathrm{f}}\right)}{l}, \\
\frac{\mathrm{d} l}{\mathrm{~d} t}=\frac{D\left(1-\theta_{\mathrm{f}}\right) C M}{l \rho \theta_{\mathrm{f}}} .
\end{gathered}
$$

Equation (24) can be solved iteratively by computer and the diffusion current (23) can then be calculated for the post-anodic peak region.

Figure 12 shows an experimentally obtained $E / I$ curve for $\mathrm{AgBr}$ film formation along with a curve calculated on the basis of the above models. From $\eta$ $=0$ to $\eta=116 \mathrm{mV}$, when $C_{\mathrm{s}}=0,(13-18)$ were used to calculate the current on the basis of the bulk solution and pore solution resistance model. At the point ' $a$ ' in Fig. $12, C_{\mathrm{s}}=0$, but $\mathrm{d} \theta / \mathrm{d} t$ is not yet equal to zero and hence further film spreading and thickening now occurs under the control of bromide ion diffusion in the pores of the $\mathrm{AgBr}$ film. In this region, (21) was utilized instead of (18) and (19) was utilized instead of (17) to calculate $\mathrm{d} \theta / \mathrm{d} t$ and $I$, respectively. At point ' $b$ ' in Fig. 12, $\mathrm{d} \theta / \mathrm{d} t$ is now equal to zero, and hence only film thickening can now occur under the control of bromide diffusion. The rate of film thickening was calculated by (24) and then $I$ was determined from (23).

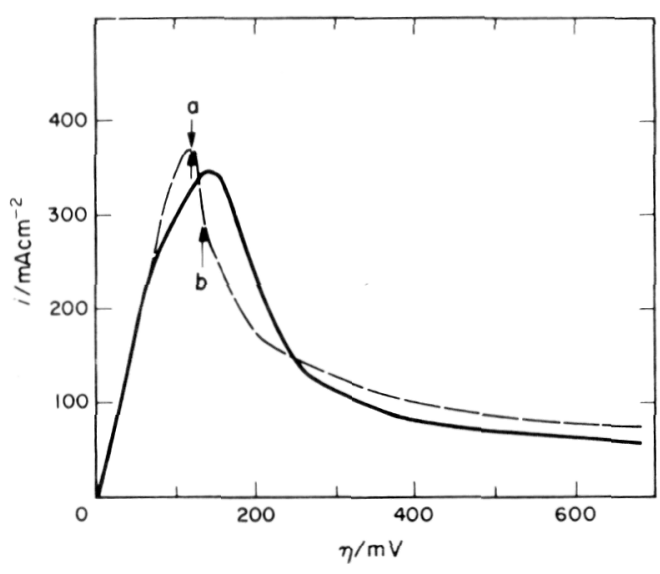

Fig. 12. Experimentally obtained (-) and calculated (--) E/I curves for $\mathrm{AgBr}$ film formation on an $\mathrm{Ag}$ rde in $1 \mathrm{moll}^{-1} \mathrm{NaBr}+5 \mathrm{moll}^{-1} \mathrm{NaClO}_{4}, \quad s=50 \mathrm{mV} \mathrm{s}{ }^{-1}, \omega$ $=7 \mathrm{~Hz}$. Film spreading and thickening occurs prior to point ' $b$ ', then, film thickening occurs under pore diffusion control.

Overall, the calculated current/potential relationships of Fig. 12 are quite close to the experimental curve and possess the same general features. Therefore, the model of a solution and pore resistance controlled current in the anodic peak region, followed by a diffusion controlled current in the post-peak region appears to be a very close simulation of the real case.

\section{SUMMARY}

A potentiodynamic study of $\mathrm{AgBr}$ film formation on a rotating $\mathrm{Ag}$ disc electrode was carried out in conjunction with Scanning Electron Microscope investigations of anodically formed $\mathrm{AgBr}$ film morphology. From this, the reaction between $\mathrm{Ag}$ and $\mathrm{Br}^{-}$ ions has been found to be very fast so that various physical processes are rate limiting.

In dilute bromide solutions, the diffusion of $\mathrm{Br}^{-}$ ions to the $\mathrm{Ag}$ electrode surface limits the rate of $\mathrm{AgBr}$ film growth. This is evidenced by the linear relationship between the anodic plateau current and $\omega^{1 / 2}$ and the independence of the current from the potential sweep rate. SEM examinations of the films formed under these conditions have shown an island type of growth rather than a compact $\mathrm{AgBr}$ film.

In concentrated bromide solutions, the initial rate limiting process is now ionic migration in the solution. A model of the nucleation of islands of $\mathrm{AgBr}$ film, and their subsequent spreading and thickening at a rate controlled by the ohmic resistance of the bulk solution and the solution in the pores of the film has yielded an excellent quantitative simulation of the observed anodic current peak. In the region of the $E / I$ curves after the peak, the diffusion of $\mathrm{Br}^{-}$ions in the pores of the film was found to be rate limiting as is evidenced by the lack of dependence of these currents on $s, \omega$ and $E$, the potential. SEM investigations have shown that the porous type of film morphology is retained even for films which are up to $10 \mu \mathrm{m}$ in thickness.

Acknowledgements - V. I. B. gratefully acknowledges the receipt of a Commonwealth Scholarship from Canada to New Zealand from the New Zealand Grants Committee.

\section{REFERENCES}

1. R. F. Amlie, H. N. Honer and P. Ruetschi, J. electrochem. Soc. 112, 1073 (1965).

2. D. Ives and G. Janz, Reference Electrodes, Academic Press, London (1961).

3. L. Slifkin, Sci. Prog. Oxf. 60, 151 (1972).

4. L. J. Kurtz, C. r. U.R.S.S. 11, 383 (1935).

5. G. W. Briggs and H. R. Thirsk, Trans. Faraday Soc. 48, 1171 (1952)

6. W. Jaenicke, R. Tischer and H. Gerischer, Z. Elektrochem. 59, 448 (1955).

7. W. Jaenicke, ibid 55, 186 (1951).

8. S. A. Awad, J. electroanal. Chem. 21, 483 (1969).

9. M. Fleischmann and H. Thirsk, Electrochim. Acta 1, 146 (1959).

10. R. D. Giles, J. electroanal. Chem. 27, 11 (1970).

11. P. Bro and N. Marincic, J. electrochem. Soc. 116(10), 1338 (1969)

12. E. Bishop and M. Riley, Analyst 98, 313 (1973).

13. H. Lal, H. R. Thirsk and W. F. K. Wynne-Jones, Trans. Faraday Soc. 47, 70 (1951).

14. K. Indira and K. Doss, Proc. Symp. Electrode Processes, p. 7. Jodhpur, India (1960).

15. T. Katan, S. Szpak and D. N. Bennion, J. electrochem. Soc. 120(7), 883 (1973).

16. T. Katan, S. Szpak and D. N. Bennion, ibid 121(6), 757 (1974).

17. S. Szpak, A. Nedoluha and T. Katan, ibid 122(8), 1054 (1975).

18. J. S. Dunning, D. N. Bennion and J. Newman, ibid 120(7), 906 (1973). 
19. S. Szpak and T. Katan, ibid 122(8), 1063 (1975).

20. W. Tiedemann and J. Newman, ibid $122(11), 1482$ (1975).

21. V. I. Birss and G. A. Wright, Electrochim. Acta, 26, 1809 (1981).

22. V. I. Birss and G. A. Wright, ibid, 27, 1 (1982).

23. M. Babai, T. Tshernikovskii and E. Gileadi, J. electrochem. Soc. 119, 1018 (1972).

24. L. Bircumshaw and A. Riddiford, Q. Rev. chem. Soc. 6, 157 (1952)
25. R. Parsons, Handbook of Electrochemical Constants, Butterworths, London (1959).

26. N. R. C. of America, International Critical Tables, (edited by E. W. Washburn) Vol. 5. McGraw-Hill, New York (1929).

27. J. Newman, J. electrochem. Soc. 113, 501 (1966).

28. W. J. Mueller, Trans. Faraday Soc. 27, 737 (1931).

29. A. J. Calandra, N. R. de Tacconi, R. Pereiro and A. J. Arvia, Electrochim. Acta 19, 901 (1974). 